\title{
Common variable immunodeficiency presenting in a girl as lung infiltrates and mediastinal adenopathies leading to severe "superior vena caval" syndrome
}

\author{
O. Sacco*, B. Fregonese*, P. Picco**, M. Faraci**, P. Facchetti+, \\ V. Pistoia+, G.A. Rossi*
}

Common variable immunodeficiency presenting in a girl as lung infiltrates and mediastinal adenopathies leading to severe "superior vena caval" syndrome. O. Sacco, B. Fregonese, P. Picco, M. Faraci, P. Facchetti, V. Pistoia, G.A. Rossi. (CERS Journals Ltd 1996.

ABSTRACT: Common variable immunodeficiency (CVID) is a primary immunodeficiency disorder characterized by decreased levels of circulating immunoglobulins (Ig) and increased susceptibility to infections.

We describe the case of a girl, progressively developing CVID, whose first clinical manifestations were noninfectious diffuse pulmonary infiltrates and rapidly developing hilar and mediastinal lymphadenopathies causing a severe "superior vena caval syndrome". Histological evaluation of surgical samples showed follicular and paracortical hyperplasia of the lymph nodes and poorly organized, non-necrotizing, noninfectious, "reactive" granulomata in lymph nodes and pulmonary tissue. Daily treatment with azathioprine and prednisone induced resolution of the intrathoracic abnormalities but was associated with a progressive decrease of circulating IgG and IgA levels and natural killer (NK) lymphocytes that was not related to treatment.

This case demonstrates that granulomatous inflammatory changes may be the first manifestations of common variable immunodeficiency, and that this disorder must be included in the differential diagnosis of lymphoid interstitial pneumonitis and of bilateral mediastinal lymph node enlargement leading to superior vena caval syndrome.

Eur Respir J., 1996, 9, 1958-1961.
*Divisione di Pneumologia **Divisione di Pediatria II and +Laboratorio di Oncologia, G. Gaslini Institute, Genoa, Italy.

Correspondence: G.A. Rossi Division of Pneumology

G. Gaslini Institute

Largo G. Gaslini 5 16147 Genoa

Italy

Keywords:

Common variable immunodeficiency

Cytomegalovirus infections

hypogammaglobulinaemia lymphoid hyperplasia

superior vena caval syndrome

Received: August 141995

Accepted after revision May 101996
Common variable immunodeficiency (CVID), also known as common variable or late-onset hypogammaglobulinaemia, is a definition used to designate a group of syndromes characterized by defective antibody formation [1]. All are associated with reduced levels of serum immunoglobulins ( $\mathrm{Ig}$ ), decreased ability to produce antibodies following antigenic challenge, and increased susceptibility to sinopulmonary infections [1-3]. Although categorized as a B-cell dysfunction, there is convincing evidence that T-cell abnormalities may contribute to the pathogenesis of this disorder, at least in some patients $[1,4]$.

Clinically, CVID is manifested most commonly in adolescence or young adulthood by recurrent infections, due to highly virulent encapsulated extracellular bacteria [3-6]. The infections usually involve the upper and lower respiratory tract and may be associated with either localized or generalized lymphadenopathy [3-5].

We describe a case of progressively developing CVID in a young girl. The first clinical manifestations were diffuse pulmonary infiltrates and rapidly developing hilar and mediastinal lymphadenopathies causing a severe "superior vena caval syndrome".

\section{Case report}

A Caucasian girl, aged 6 yrs, was referred to our institute from another hospital in March 1992 following the persistence of diffuse pulmonary infiltrates of unknown aetiology, despite treatment with antibiotics (imipenem and erythromycin) and corticosteroids (prednisone 0.75 $\mathrm{mg} \cdot \mathrm{kg}^{-1}$ daily). She had an episode of bacterial pneumonia when she was 1 year old, and several episodes of sinusitis and bronchitis, which responded to treatment with antibiotics and corticosteroids, in the following years.

On admission, she was in mild respiratory distress and chest roentgenograms showed bilateral diffuse alveolar infiltrates. The white blood cell counts were $9.9 \times 10^{9}$ cells $\cdot \mathrm{L}^{-1}$ (neutrophils $70 \%$, lymphocytes $17 \%$, monocytes $7 \%$ and eosinophils 3\%). Serum protein electrophoresis was normal and Ig levels were within the normal range (table 1). Samples of blood, pharyngeal aspirate and urine were cultured and the results were negative. Skin reactivity to recall antigens and phagocytic oxidative metabolism were normal, whilst no abnormalities in lymphocyte subpopulations were found, except for low 
Table 1. - Serum immunoglobuin levels performed at different time intervals

\begin{tabular}{llcr}
\hline Date & \multicolumn{2}{l}{ Serum immunoglobulin levels } & $\mathrm{mg} \cdot \mathrm{dL}^{-1}$ \\
\cline { 2 - 4 } & IgG & $\operatorname{IgM}$ & $\operatorname{IgA}$ \\
\hline $6 / 5 / 1992$ & 698 & 231 & 63 \\
$2 / 11 / 1993$ & 298 & 198 & 12 \\
$23 / 3 / 1994^{*}$ & 133 & 238 & $<7$ \\
$16 / 5 / 1994^{*}$ & 189 & 276 & $<7$ \\
$8 / 2 / 1995^{*}$ & 264 & 392 & $<7$ \\
$7 / 7 / 1995^{*}$ & 260 & 109 & $<7$ \\
$25 / 10 / 1995^{*}$ & 199 & 101 & $<7$ \\
\hline
\end{tabular}

Serum levels of different immunoglobulins were measured by ELISA. *: values were determined at least 25 days after therapeutic i.v. immunoglobulin infusion. Ig: immunoglobulin; ELISA: enzyme-linked immunosorbent assay.

levels of CD19+ B-cells (table 2). Treatment with imipenem and erythromycin was initiated and prednisone was tapered in the following 3 days.

On day 5, the clinical conditions worsened with development of progressive respiratory distress, and engorgement of the jugular veins. The chest radiograph disclosed extension of the pulmonary infiltrates with decreasing lung volumes, and Cytomegalovirus (CMV) was detected by immunoperoxidase staining in urine and peripheral blood polymorphonucleates (PMNs) and bronchoalveolar lavage (BAL) cells. Treatment with ganciclovir i.v. was initiated and resulted in a sharp decrease in the number of CMV+ peripheral blood PMNs without concomitant changes in clinical conditions. A superior vena caval syndrome developed and the chest radiograph demonstrated enlargement of the mediastinum (fig. 1), while computed tomographic (CT) scans showed marked enlargement of lymph nodes in the mediastinum and the retroperitoneum.

Because of a presumptive diagnosis of lymphoma, open lung biopsy was performed. Histologically, the lung parenchyma showed bronchiolitis obliterans, with interstitial inflammation and small noncaseating granulomata, whilst lymph nodes demonstrated follicular and paracortical hyperplasia with poorly organized, non-necrotizing granulomata. Standard histological, cultural and molecular biological tests performed on biopsy materials for detection of fungi, mycobacteria, Pneumocystis carinii, Epstein

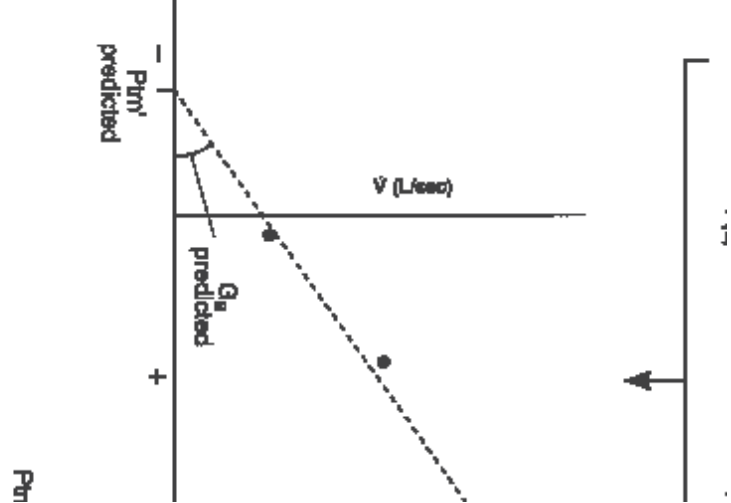

Fig. 1. - Chest roentgenogram of the patient, 10 days after admission, showing enlargement of the mediastinum, with widening of the carinal angle, and extension of the pulmonary infiltrates with decreased lung volumes.

Barr virus (EBV) and CMV were all negative. Two consultant pathologists (E. Jaffe, NIH, Bethesda, MD, USA, and F. Basset, INSERM 82, Paris, France) described these findings as "reactive", but nonspecific for any defined disease, including sarcoidosis and Wegener's granulomatosis.

Prednisone ( $2 \mathrm{mg} \cdot \mathrm{kg}^{-1}$ daily) was introduced and resulted in a sudden improvement of the clinical conditions and chest roentgenographic abnormalities. Two weeks later, after progressive reduction of prednisone to 0.75 $\mathrm{mg} \cdot \mathrm{kg}^{-1}$ daily, the patient again became febrile and dyspnoeic, and chest radiographs demonstrated that the pulmonary infiltrates were again increased in size and number. Azathioprine $\left(1.5 \mathrm{mg} \cdot \mathrm{kg}^{-1}\right)$ was introduced with progressive improvement of the clinical conditions.

In the period July 1992 to February 1995, chest radiographs showed persistence of a reticulonodular pattern, which was associated with a mild decrease in transcutaneous arterial oxygen saturation $\left(\mathrm{SaO}_{2}\right)(88-92 \%)$. Several attempts to decrease the dosages of one of the two drugs resulted in relapse of fever, increase of pulmonary infiltrates, and enlargement of mediastinal lymph nodes. Interestingly, the follow-up evaluations of the patients demonstrated: 1) a progressive decrease of blood $\operatorname{IgA}$ and IgG levels (table 1) (requiring, from January 1993, replacement therapy with i.v. $\gamma$-globulin preparations);

Table 2. - Immunophenotypic analysis of patient's peripheral blood mononuclear cells performed at different time intervals

\begin{tabular}{lcccccc}
\multicolumn{6}{c}{ Date } & \multicolumn{6}{c}{ Surface markers $\%$ positive cells } \\
\cline { 2 - 6 } & CD3+\# & CD4+\# & CD8+\# & CD19+\# & CD16+\# & CD3/HLA-DR+* \\
$6 / 5 / 1992$ & 84 & 46 & 33 & 2 & 7 & 12 \\
$2 / 11 / 1993$ & 98 & 42 & 37 & 11 & 8 & 11 \\
$23 / 3 / 1994$ & 93 & 46 & 37 & 6 & $<1$ & 22 \\
$16 / 5 / 1994$ & 89 & 38 & 38 & 7 & 1 & 37 \\
$8 / 2 / 1995$ & 98 & 37 & 53 & 2 & $<1$ & 39 \\
$25 / 10 / 1995$ & 94 & 35 & 42 & 5 & 1 & 35 \\
\hline
\end{tabular}

Peripheral blood mononuclear cells were isolated on a Ficoll-Hypaque density gradient and stained with the following fluorochrome-conjugated murine monoclonal antibodies (MoAbs): Leu 2 (CD8), Leu 3 (CD4), Leu 4 (CD3), Leu 12 (CD19) and HLA-DR from Becton-Dickinson, Sunnyvale, CA, USA; CD16 from Serotec, Italfarmaco, Milan, Italy. Single and double staining studies were carried out. Samples were analysed by flow cytometer (Fac Star; Becton-Dickinson). \#: single staining study; *: double staining study. HLA-DR: human leucocyte antigen-DR. 
2) a sharp decrease of circulating natural killer (NK) cells; and 3) persistent detection of CMV both in the urine and blood PMNs, despite treatment with ganciclovir.

From January 1993, several acute respiratory infectious episodes occurred and Pseudomonas aeruginosa and Streptococcus pneumoniae were isolated from BAL fluid and blood cultures on two occasions. CT scans of the thorax, performed in February 1995 and October 1995, showed, in addition to the interstitial involvement and to the mild enlargement of mediastinal lymph nodes, the presence of bronchiectasis on both lung bases.

From February 1995, prednisone doses were progressively tapered to $0.50 \mathrm{mg} \cdot \mathrm{kg}^{-1}$ every other day, and from July 1995 to $0.17 \mathrm{mg} \cdot \mathrm{kg}^{-1}$ (=5 mg) every other day, whilst the azathioprine doses were tapered to $0.75 \mathrm{mg} \cdot \mathrm{kg}^{-1}$ from July 1995. These alterations did not induce any change in Ig serum levels or in the proportions of circulating NK lymphocytes.

\section{Immunological evaluation}

Evaluation of the immunophenotype of blood mononuclear cells (BMCs) during the follow-up demonstrated (table 2): 1) a progressive decrease of the CD4/CD8 ratio that finally became inverted; 2) virtual disappearance of the CD16+ NK cells; and 3) a "fluctuation" of the proportion of activated human leucocyte antigen-DR positive (HLA-DR+) T-cells, while CD19+ B-cells remained in the low-normal range.

Peripheral blood T-cell proliferative responses to a mitogen (phytohaemagglutinin (PHA)) or tetanus toxoid and Candida antigens were strong on admission, and still present in October 1995, indicating a functional T-cell compartment. In contrast, NK cell activity (investigated by incubating freshly isolated mononuclear cells with ${ }^{51} \mathrm{Cr}$ labelled K562 erythroleukaemia cells for $4 \mathrm{~h}$ ) was normal on admission (18\% at an effector/target ratio of 40:1), whereas it was virtually absent 3 yrs later. This finding may be related to the disappearance of CD16+ NK cells (table 2) and/or to the immunosuppressive treatments. However, no changes in the proportion of NK cells or in NK activity were detected when prednisone was progressively reduced.

Finally, studies aimed at clarifying the nature of the immune deficiency were carried out during the disease course by co-culturing blood T- or B-cells from the patient with B- or T-cells from a normal donor in the presence of pokeweed mitogen (PWM). Evaluating Ig concentrations (by enzyme-linked immunosorbent assays (ELISA)) in the supernatant after 7 days culture, the following results were obtained: 1) patient T-cells promoted production of $\operatorname{IgG}$ and $\operatorname{IgA}$ by normal but not by patient B-cells in the presence of PWM, suggesting that the latter cells were intrinsically defective; 2) normal T-cells did not induce $\mathrm{IgG}$ or IgA production by patient B-cells in the presence of PWM, further supporting the hypothesis of an intrinsic abnormality of the patient B-cells; and 3) patient T-cells suppressed IgA synthesis by normal Bcells cultured with normal T-cells and PWM.

\section{Discussion}

In this case report, we describe the occurrence of diffuse pulmonary infiltrates and hilar adenopathies lead- ing to superior vena caval syndrome in a young girl, who subsequently developed severe reduction of circulating $\mathrm{IgA}$ and IgG. The clinical course and the in vitro tests on blood B- and T-cells led to the diagnosis of common variable immunodeficiency (CVID) with a quite unusual presentation.

CVID is a heterogeneous disease, invariably associated with immunoglobulin deficit, but with different involvement of the various immunoglobulin classes. The most common pattern is an extreme reduction of circulating $\operatorname{IgG}$, frequently also involving $\operatorname{Ig} \mathrm{A}$ and $\operatorname{IgM}[1,4$, 7]. The common defect in CVID is a block in the normal differentiation of B-lymphocytes into antibody-producing plasma cells; circulating B-cells appear to be immature but their number may be normal $[1,8]$. The mechanisms involved are heterogeneous, and include: 1) intrinsic defects in the ability of B-cells to synthesize and/or secrete immunoglobulin [9-10]; 2) abnormalities in regulatory T-cells [1,9-11]; 3) defective interaction between T- and B-cells [12]; and 4) rarely, autoantibodies to either B- or T-cells [7-10].

Immunological studies showed that in this patient the pathogenesis of immunodeficiency was likely to be attributable to a B-cell defect. The latter conclusion was supported by the following observations: 1 ) the patient's $\mathrm{T}$-cells were functionally competent, as suggested by the normal skin reactivity to recall antigens, the normal proliferative responses to PHA or antigens, and the near normal helper function versus normal B-cells (these features persisted over time in spite of the immunosuppressive treatment); and 2) the patient's B-cells did not produce $\mathrm{IgG}$ or $\operatorname{IgA}$ in vitro in the presence of either autologous or normal T-cells and PWM.

The nature of the factors responsible for the progressive deterioration of B-cell function in our patient is unknown. The first possibility is that the sharp fall of $\operatorname{Ig} \mathrm{A}$ and $\mathrm{IgG}$ serum concentrations represents a manifestation of the natural history of CVID. An alternative, but not mutually exclusive, explanation is that the immunosuppressive treatment with prednisone and azathioprine may have contributed to the pathogenesis of hypogammaglobulinaemia. However, when azathioprine and/or corticosteroid doses were reduced, no increase in the concentrations of serum $\operatorname{IgG}$ or $\operatorname{IgA}$ was detected. Finally, it is intriguing that, in the PWM experiments, the patient's T-cells suppressed IgA, but not IgG production by normal B-cells cultured with normal Tcells. The latter observation may be consistent with the reported role of suppressor T-cells in the pathogenesis of a subset of CVID cases [8].

CVID is usually recognized in children or young adults; affected individuals have a history of recurrent infections, including sinusitis, otitis, bronchitis and pneumonia, leading in some patients to bronchiectasis. Roentgenographic abnormalities suggesting bronchiectasis were demonstrated by CT scans in our patient. Since IgG is the principal antibody promoting phagocytosis of encapsulated bacteria, the most common microorganisms causing infections in CVID are S. pneumoniae and Haemophilus influenzae, followed by Staphylococcus aureus and Pseudomonas aeruginosa [9-10]. These infections were demonstrated in our patient. In addition, an increased frequency of viral infections (hepatitis $\mathrm{C}$ virus (HCV) [10], CMV and EBV [13-14]), of autoimmune 
disorders [1, 2, 5, 14], malignant gastrointestinal neoplasms, and lymphoid lesions $[1,2,6,15]$ is also reported in patients with CVID.

Lymphoid hyperplasia and granulomata, associated, as in this patient, with lymphoid interstitial pneumonitis [14], have been described in several patients with CVID during the course of the disease, and may be related to the basic B-cell/T-cell abnormalities but also to viral or mycobacterial infections [5,6]. These lesions, that may occasionally lead to a true sarcoid-like syndrome, do not usually precede the appearance of disturbances in immunoglobulin synthesis, and undergo spontaneous regression [9] without requiring treatment with immunosuppressive agents. The "aggressive" characteristics of lymphoid hyperplasia, as observed in this patient, may be related to associated chronic viral infections (CMV, EBV and HCV) and/or to a peculiar genetic background. Although, by in situ hybridization, no evidence of EBV was found in lung and lymph node biopsies, CMV was detected within BAL macrophages.

Finally, the patient, born to first degree cousins, has a younger brother (now 7 yrs of age), who developed a severe immune-mediated haemolytic anaemia, an autoimmune disorder with a high incidence in CVID patients and their relatives $[1,16]$. Initially CVID was considered to be a truly sporadic or acquired defect, but more recently considerable evidence has emerged that genetic mechanisms related to polymorphism of major histocompatibility complex (MHC) genes are involved in at least some patients with this syndrome [17].

In summary, this case report demonstrates that lymphoid hyperplasia and granulomatous inflammatory changes may be the first manifestations of common variable immunodeficiency, and that this disorder must be included in the differential diagnosis of lymphoid interstitial pneumonitis and of bilateral mediastinal lymph node enlargement leading to superior vena caval syndrome.

\section{References}

1. Rosen FS, Cooper MD, Wegcwood RJP. The primary immunodeficiencies. $N$ Engl J Med 1995; 333: 431-440.

2. Hermans PE, Diax-Buxo JA, Stobo JD. Idiopathic lateonset immunoglobulin deficiency: clinical observation in 50 patients. Am J Med 1976; 61: 221-237.

3. Cunningham-Rundles C. Clinical and immunological analyses of 103 patients with common variable immunodeficiency. J Clin Immunol 1989; 9: 22-33.

4. Wright JJ, Wagner DK, Blaese RM, Hagengruber C,
Waldmann TA, Fleisher TA. Characterisation of common variable immunodeficiency: identification of a subset of patients with distinctive immunophenotypic and clinical features. Blood 1990; 76: 2046-2051.

5. Hausser C, Virelizier JL, Buriot D, Griscelli C. Common variable hypogammaglobulinemia in children: clinical and immunologic observation in 30 patients. Am J Dis Child 1983; 137: 833-837.

6. Sander CA, Mederois LJ, Weiss LM, Yano T, Sneller T, Jaffe ES. Lymphoproliferative lesions in patients with common variable immunodeficiency syndrome. Am J Surg Pathol 1992; 16: 1170-1182.

7. Rosen FS, Cooper MD, Wedgwood RJ. The primary immunodeficiencies (second of two parts). $N$ Engl $J$ Med 1984; 311: 325-342.

8. Waldmann TA, Durm M, Broder S. Role of suppressor T-cells in the pathogenesis of common variable hypogammaglobulinemia. Lancet 1974; ii: 609-613.

9. Waldmann TA. Immunodeficiency diseases: primary and acquired. In: Samter M, Talmage DW, Frank MM, Austen KF, Claman HM, eds. Immunological Diseases. 4th edn. Boston, Little Brown and Co., 1988; Vol. 1: pp. $411-465$

10. Sneller MC, Strober W, Eisenstein E, Jaffe JS, Cunningham RC. NIHAU conference: new insights into common variable immunodeficiency. Ann Intern Med 1993; 118: 720-730.

11. Sneller MC, Strober W. Abnormalities of lymphokine gene expression in patients with common variable immunodeficiency. J Immunol 1990; 144: 3762-3769.

12. Farrington M, Grosmaire LS, Nonoyama S, et al. CD40 ligand expression is defective in a subset of patients with common variable immunodeficiency. Proc Natl Acad Sci USA 1994; 91: 1099-1103.

13. Doke WD, Simon HU, Fietze E. Cytomegalovirus infection and common variable immunodeficiency. Lancet 1991; 338: 1597.

14. Hermaszewski RA, Weber AD. Primary hypogammaglobulinemia: a survey of clinical manifestations and complications. Q J Med 1993; 86: 31-42.

15. Sander CA, Medeiros LJ, Weiss LM, Yano T, Sneller MC, Jaffe ES. Lymphoproliferative lesions in patients with common variable immunodeficiency syndrome. Am J Surg Pathol 1992; 16: 885-895.

16. Wong JT, Girardet C. A 58 year old man with common variable immunodeficiency, splenomegaly and hemolytic anaemia. N Engl J Med 1995: 332: 663-672.

17. Shaffer FM, Palermos J, Zhu ZB, Barger BO, Cooper $\mathrm{MD}$, Volanakis JE. Individuals with IgA deficiency and common variable immunodeficiency share polymorphism of major histocompatibility complex class III genes. Proc Natl Acad Sci 1989; 86: 8015-8019. 